\title{
The dilemma of "plastic limit order" and Its enlightenment to life custom regulation
}

\author{
Yin Long \\ Harbin University of Commerce, Harbin, China \\ yin_long@126.com
}

Keywords: life custom "plastic limit order” regulation

\begin{abstract}
Plastic limit order" although obtained certain result in the early stage of promulgation, consumers abandoned original totally dependent on plastic shopping bags consumption habits, with the passage of time, consumers have become accustomed to the "charge" system of the plastic shopping bags, paid use seems to form a new shopping concept, has become universal adherence behavior. During the implementation of the "plastic limit order", policy execution gradually deviate from the expected goal. This paper evaluates the "plastic limit order" execution effect, and based on how to effectively regulate living customs, policy suggestion is proposed.
\end{abstract}

\section{Introduction}

With the progress of social science and technology, the development of modern civilization and the transformation of the modern lifestyle and life philosophy, some traditional ideas, habits, and the value orientation of modern society seem to be at odds, have not adapt to the current social development, must be adjusted through policies and regulations.

Using plastic bags for shopping has become people living habits over the years, but in recent years as China is accelerating the process of urbanization, the excessive expansion of the urban population, a large number of plastic bags over the abuse, which makes the urban environment pollution be far more than expected. "White pollution" has seriously affected the living environment and quality of life, a series of social negative effects also is more and more troubling. Since, China State Council on December 31, 2007 issued the "production and sales restrictions on the use of plastic shopping bags," which is, we usually call "plastic limit order". Described in this article, "plastic limit order" is in a broad sense, including many "plastic limit" policies and regulations.

Before the implementation of the "plastic limit order", due to fierce competition in the industry, except for a few large foreign supermarket, general domestic supermarkets were in accordance with the practice always providing customers with free plastic shopping bags, and consumers developed a bad habit of extravagance. "Plastic limit order" prescribed method of compensation for the use of plastic bags had a significant impact on consumers, the number of plastic bags use in a period of time had fallen sharply. One store of Carrefour, for example, in the fist year after "limit plastic order" implementation, the consumption of plastic shopping bags from 340 thousands in May were sharply reduced to 80 thousands in June. That made satisfactory results. But, with the passage of time, consumers have become accustomed to the "charge" system of the plastic shopping bags, paid use seems to form a new shopping concept, has become universal adherence behavior. Because of the cost of the plastic bag is low, only a few customers bring their own shopping bags, most of the customers are in compliance with the rules of compensation for the use.

The implementation effect of the "plastic limit order" is not as good as expected. In the initial implementation, through the government department coordination, actively implement, and mandatory administrative control means, in retail establishments "plastic limit" had achieved some success. But high execution cost and difficulties to change consumer habits made the "plastic limit" in the face of "mass illegal" to no avail. Although large supermarket chains and other formal market implement the system of paid use for plastic bags, but cheap plastic bag costs makes "paid to buy" has become a new consumption habit of the masses. In the farmer's market, such as commodity retail markets, the number of ultra-thin plastic bags also gradually returns to the status of the 
"plastic limit" before. "Plastic limit order", which is intended to regulate consumer behavior, has actually been ineffective, and gradually went into a "misconduct" quagmire.

\section{"Plastic limit order" execution effect evaluation}

Policy effectiveness evaluation. In order to investigate the actual use of plastic shopping bags, We select part of the supermarket and farmers' markets in Harbin as sample, and conduct a random survey in the form of questionnaire and field observation. Research found that, both in large supermarket and farmer's market, most of the customers do not have the habit of bring shopping bags, paid to provide the use of supermarket shopping bags account for the vast majority of customers, and more than 95\% of consumers must use shopping bags while shopping, only a very few are readily belongings. One Carrefour supermarket, for example, in the investigation of the 246 people, 28 people carrying shopping bags, 204 people using plastic shopping bags, 14 people not using plastic bags.

However, after the implementation of "plastic limit order", the number of Shredded bags on roll in the chain of supermarkets rose sharply. Since the packaging of vegetables with Shredded bags was not within the scope of the provisions of the "plastic limit", a large number people began to use Shredded bags on roll from fresh fruits and vegetables counter. Free Shredded bags replaced the plastic shopping bags to a certain extent. "Plastic limit" policy itself existed loopholes, which olny changed the form of using plastic bags, and did not reduce the use of plastic bags from the total.

Scenario analysis-consumer attitudes. The regulation of paid use in "plastic limit order" is challenge to the consumer's habit of free plastic bags. Since the consumer is the direct object of policy implementation, policy effect depends to a great extent on consumer's attitude to the "plastic limit" policy and the degree of dependence on the use of plastic bags. Many consumers do not understand the specific contents of the "plastic limit order" and regulations to ban the use of ultra-thin plastic bags. Most consumers do not approve of paid use to plastic shopping bags, only a handful of customers that can understand. There are some consumers think that our country should formulate the unified plastic bag supply price, provide plastic bags, which are paid for, to all retail establishments in a fair way, and use the income to environmental protection projects.

Social proof-on plastic bag manufacturers and retail premises. "Plastic limit order" clearly stipulates that ultra-thin plastic bags must be eliminated, the production, business sales, consumer use of ultra-thin plastic bags are prohibited. Completely ultra-thin plastic bags banned policy, produced a huge pressure on some plastic bags production enterprises. Part of the enterprises, those production technology did not pass, overall on a smaller scale, limited annual output, had to stop the production and business operation, was forced to turn to other industries. But the policy didn't formulate relevant policies and provide incentive measures to enable manufacturers face enormous conversion, bankruptcy costs. Eventually, under pressure to survive and driven by the interests, enterprises continued to invest in production facilities, re-selected the venue, produced inferior ultra-thin plastic bags. The number of unqualified plastic bag manufacturers has returned to the level before the implementation of the policy.

Commodity retail establishments provided free plastic shopping bags before "plastic limit order" promulgation, "plastic limit order" ban illegal plastic shopping bags, paid for legal plastic shopping bags. This policy had great influence on the retail establishments. Supermarkets and large stores actively supported this policy, which changed their operating costs into sales revenue. Some merchants provided reusable shopping bags to consumers for free, to make marketing and brand spread, that not only improved their visibility, but also in the consumers' mind set up a positive image of the positive performance of environmental responsibility. However, almost all the farmers markets, fruit stalls still continued to provide illegal plastic shopping bags in free, and they were not punished by the relevant departments for free supply. This showed that the "plastic limit order" did not cause the attention of market regulators and law enforcement personnel. Paid to provide system had not play the actual effectiveness in farmers' markets and other decentralized market. 


\section{"Plastic limit order" improvement scheme}

"Divide and conquer" mode. A total ban on the use of plastic bags would face a huge cost $t$ of the implementation issues to the government, "plastic limit" can carry out "divide and conquer" approach, according to different places and different levels of consumer groups, implement different management methods. On the one hand, in supermarkets and shopping malls, we can offset the amount of consumption for not using plastic bags to consumers, in order to inspire consciously implementation of the "plastic limit order", which subtly guide consumers keep into a new lifestyle. It may be more effective than pay for use, and also reflects the government's people-oriented concept of governance. On the other hand, we perform shopping bag united system in farmer's fragmented markets, all stalls in the market not provide any shopping bags, special sales window is set by the market management department, its operating expenses paid by the various stalls. The consumers, who do not bring their own shopping bags, can go to the window buy plastic bags and environmental protection bags with unified market name. After being used, unified market providing shopping bags, may at any time be returned to the point of sale, original price for intact recovery, and damages ones in accordance with recycling prices.

Share responsibility of tax incentive mode. For the issues, those unequal distribution of responsibility of "plastic limit" and all environmental responsibility attributed to consumers, we propose to take bag tax system, to impose certain taxes to manufacturers, distributors, and consumers. Production enterprises and businesses in the field of circulation, as "rational economic man", pursue their own interests, do not take the initiative to promote the realization of the public interest. Through certain tax, use market to increase the manufacturer's production costs, and to increase the sense of the social responsibility of the sellers, in the principle of fairness, let everyone have formed consciousness that pay for his inappropriate economic behavior. In fact, through the collection of taxes to reduce consumption of plastic shopping bags, was a way to implement and proved that the effect was significant in other countries early. Use tax economic incentives for the "plastic limit" suits China's national conditions, since such a vast administrative areas in China, the rigid "command-to obey" administrative means obviously don't work, we need more flexible economic incentive tools. Taxes not only are levied low running costs, but also avoid overlapping authority cross or policies from different departments, adn may reduce the "rent-seeking" opportunities in implementation of policies.

\section{How to effectively regulate living customs.}

Policy needs certain feasibility.The invalidation of the "plastic limit order" is partly because of that it does not specify specific rules for the operation and related incentive measures."Plastic limit" policy objects involved in the production, circulation and consumption, the target number is too big, and the behaviors before policy are difficult to adjust, that make the "plastic limit" no actual operability. Regulation of life custom class policies can not adopt a "one size fits all" model, their effective implementation often need to narrow the target groups range, or take a "divide and conquer" approach, adopt different coping strategies for different people, in a progressive way to realize people obey and accept regulation policy.

Regulation of life custom class policy must be carried out cost-benefit comparison. Regulation living custom class policy challenges not the behavior of the general, but regulates the behavior of people's lives, habits, morality, and custom. So we must pay more attention to the cost - benefit comparison, whether the new customs adjusted by the social mainstream value judgment can be accepted by people or not, whether it is in line with the public's heart. "Plastic limit order" ignores the cost-benefit comparison, on the one hand, wrongly assessed the cost of changing people's behavior, on the other hand, blindly take administrative control, ignoring the comparison with other means of intervention.

Increase investment in ideology. For regulating living custom policy, the ideological investment is extremely important. One important way to invest is to promote its ideology, in the formulation and implementation process of regulation policy, we must carry out wide and in-depth publicity and 
education activities. By actively guiding the social public opinion tendency to form the social mainstream ideology, the policy requires judgment, accumulates regulation practice resources, avoids too little ideology investment to influence the actual effect.

\section{Conclusions}

"Plastic limit order" is in order to resolve "white pollution", caused by people's uncontrolled consumption of plastic bages. But the result of its execution is not optimistic, the execution results overwhelmed in the face of mass to break the law, gradually into a dilemma.The problems caused by the policy is not only its own shortcomings, but also the policy level required to perform, more importantly, it makes us think, living custom regulation is not only can implement good by instinct. "Plastic limit order" is just a microcosm of the living custom policy regulation, in the face of the powerful custom basis, the authorities should reference the experience of effective policy, in the regulation and reform of life custom, avoid mistakes like "plastic limit order", whether the massive cost of policy making, or the waste of resources in policy implementation, is a huge consumption of social capital. Through research, this paper argues that customs regulation policies in addition to he actual operation should need certain feasibility, the policy must focus on cost-benefit comparison, at the same time, to build the corresponding propaganda and supervision mechanism, increase the penalties on the implementation, increase the investment of ideology. Only then would the regulation living custom policy may not be "overhead".

\section{Acknowledgements}

This work was financially supported by Ministry of Education of China (10YJA790203),and Graduate student innovation research project (YJSCX2015-349HSD).

\section{References}

[1] To limit production and sales of the plastic shopping bags notice [Z]. China Office (2007) no. 72 files.

[2] Shen Ying, Discussion of the meaning of "plastic limit order" and its implementation [J]. Science and Technology Association Forum, 2009 (4).

[3] The resurgence of ultra-thin plastic bags, sales before and after Plastic limit [N]. Guangzhou daily, 2010-8-13(6).

[4] Dou Wei, Wang Yong, "Plastic limit" Policy Analysis and Countermeasures for effective implementation [J], Science and management, 2012 (7).

[5] International Food Packaging Association, "Plastic limit" the fifth anniversary report [J], Goods and quality, 2013(6).

[6]Wu Yiqing, Change and Rever beration after Banon Free Plastic Bags in China[J], Environmental Science and Management, 2009(1).

[7] Xu Suolin, Comment on Plastic Limit Order Implementation Effect and Countermeasures [J], Ecological Economy, 2010(4). 